\title{
Notation conventions
}

Signs are represented in the form of English glosses in small capitals. These glosses do not provide any information about the phonological form of signs, nor do they indicate whether signs are one- or two-handed.

Manual signs are glossed linearly, while non-manual elements are represented as abbreviations on a line above the manual glosses, indicating their scope. Only non-manual elements that are directly relevant to an example or are necessary for the correct interpretation of the construction (e.g. in the case of a headshake for negation) are represented.

All conventions used in this book are listed on the next couple of pages. An example sentence illustrating some of the most commonly used glossing conventions is represented in (i). Glossed examples in the text that are reproduced from other works are adapted, if necessary, to conform to the glossing conventions below.

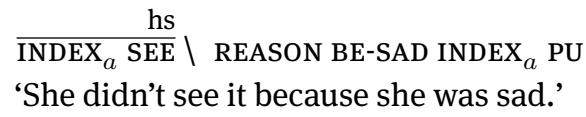




\section{Manual signs:}

\begin{tabular}{|c|c|}
\hline Gloss & Description \\
\hline SIGN & $\begin{array}{l}\text { Manual signs are glossed in small capital letters in the English word(s) most closely } \\
\text { approximating their meaning. }\end{array}$ \\
\hline SIGN-SIGN & $\begin{array}{l}\text { If several words are required to gloss a single sign, these words are connected by } \\
\text { a hyphen, as in e.g. LET-KNOW. }\end{array}$ \\
\hline SIGN++ & $\begin{array}{l}\text { Reduplication of a sign, e.g. to express plurality, is indicated by a plus symbol. } \\
\text { Each symbol represents a reduplication cycle. }\end{array}$ \\
\hline dh: / ndh: & $\begin{array}{l}\text { In examples in which at least one one-handed sign is articulated by the signer's } \\
\text { non-dominant hand (ndh) while the other signs are articulated with the dominant } \\
\text { hand (dh), the glosses for manual signs are represented on two lines preceded by } \\
\text { 'dh:' and 'ndh:'. }\end{array}$ \\
\hline SIGN........ & $\begin{array}{l}\text { Indicates that the final configuration of a sign is held while the other hand contin- } \\
\text { ues signing. }\end{array}$ \\
\hline $\mathrm{CL}(\mathrm{x}): \mathrm{xxx}$ & $\begin{array}{l}\text { Classifiers and classifier predicates are indicated with the gloss CL, followed by } \\
\text { a handshape specification between brackets, e.g. ( }) \text {, and a description of the } \\
\text { meaning of the classifier or classifier predicate. }\end{array}$ \\
\hline INDEX $_{x}$ & $\begin{array}{l}\text { Pointing signs are represented by the glosS INDEX followed by a subscript, which } \\
\text { indicates a particular location in the signing space. ' } 1 \text { ' refers to a location on } \\
\text { or close to the signer's body; ' } 2 \text { ' refers to the location of the addressee; letter } \\
\text { subscripts ('a'; 'b') abstractly represent other locations in the signing space. When } \\
\text { there are two pointing signs within a single example, the first INDEX is followed by } \\
\text { the subscript 'a' and the second by 'b'. }\end{array}$ \\
\hline Poss $_{x}$ & $\begin{array}{l}\text { A possessive pronoun, signed with a } \\
\text { the subscript. }\end{array}$ \\
\hline $\operatorname{VERB}_{x}$ & $\begin{array}{l}\text { Verb whose place of articulation aligns with a locus in the signing space, associated } \\
\text { with a referent or location, to express agreement. The subscript specifies the } \\
\text { location according to the principles explained for INDEX }{ }_{x} \text { above. Occassionally, } \\
\text { the subscript 'c' is used to highlight that a verb is articulated at the center of the } \\
\text { signing space. }\end{array}$ \\
\hline $\operatorname{VERB}_{(x)}$ & $\begin{array}{l}\text { Verb whose place of articulation aligns with a location in the signing space asso- } \\
\text { ciated with a referent or location, where the alignment might be a phonological } \\
\text { coincidence rather than a genuine expression of agreement. }\end{array}$ \\
\hline $\operatorname{VERB}_{x *}$ & $\begin{array}{l}\text { Verb with a place of articulation in the signing space that does not correspond to } \\
\text { a location previously associated with a referent or location. }\end{array}$ \\
\hline${ }_{x} \mathrm{VERB}_{y}$ & $\begin{array}{l}\text { Verb that moves from one location to another. The subscripts specify the initial } \\
\text { and final locations according to the principles explained for INDEX } \text { above. The }_{x} \\
\text { subscript types }{ }_{(x)} \text { and }{ }_{x *} \text { (see above) are also used. }\end{array}$ \\
\hline PU & Palm-up sign, a particle with a variety of discourse-related functions. \\
\hline$S-1$ & Fingerspelled words are glossed as individual letters separated by hyphens. \\
\hline 1 & A clause boundary or a clear prosodic boundary, e.g. to signal topicalization. \\
\hline
\end{tabular}


Non-manual elements:

\begin{tabular}{|c|c|}
\hline Gloss & Description \\
\hline $\mathrm{hn}$ & Head nod, e.g. for affirmation. \\
\hline hs & Headshake, to express negation. \\
\hline re & $\begin{array}{l}\text { Raised eyebrows, e.g. to mark different types of subordinate clauses or topicalized } \\
\text { constituents. }\end{array}$ \\
\hline fr & Frowning of the eyebrows, e.g. to express uncertainty. \\
\hline rs & $\begin{array}{l}\text { Role-shift markers; typically a combination of body lean, a change in the direction } \\
\text { of eye gaze, and a change in facial expressions. }\end{array}$ \\
\hline 'word' & Mouthing of a (German) word. \\
\hline
\end{tabular}


